\title{
Lead Coolant Test Facility Development Workshop
}

\author{
Paul A. Demkowicz
}

June 2005

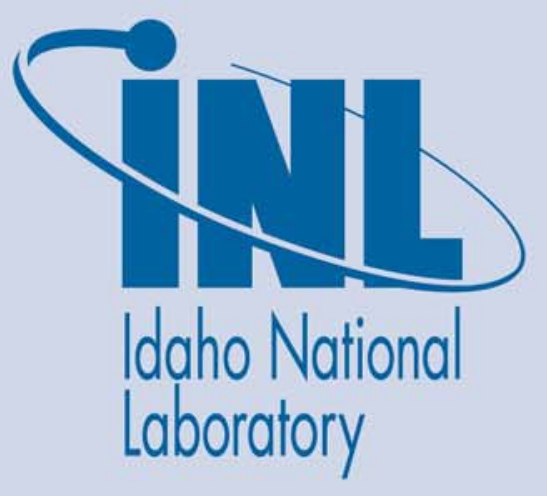

The INL is a U.S. Department of Energy National Laboratory operated by Battelle Energy Alliance 


\title{
Lead Coolant Test Facility Development Workshop
}

\author{
Paul A. Demkowicz
}

June 2005

Idaho National Laboratory Nuclear Fuels and Materials Idaho Falls, Idaho 83415

Prepared for the

U.S. Department of Energy

Office of Nuclear Energy, Science, and Technology

Under DOE Idaho Operations Office

Contract DE-AC07-05ID14517 



\section{OVERVIEW}

A workshop was held at the Idaho National Laboratory on May 25, 2005, to discuss the development of a next generation lead or lead-alloy coolant test facility. Attendees included representatives from the Generation IV lead-cooled fast reactor (LFR) program, Advanced Fuel Cycle Initiative, and several universities. Several participants gave presentations on coolant technology, existing experimental facilities for lead and lead-alloy research, the current LFR design concept, and a design by Argonne National Laboratory for an integral heavy liquid metal test facility. Discussions were focused on the critical research and development requirements for deployment of an LFR demonstration test reactor, the experimental scope of the proposed coolant test facility, a review of the Argonne National Laboratory test facility design, and a brief assessment of the necessary path forward and schedule for the initial stages of this development project. This report provides a summary of the presentations and roundtable discussions. 



\section{CONTENTS}

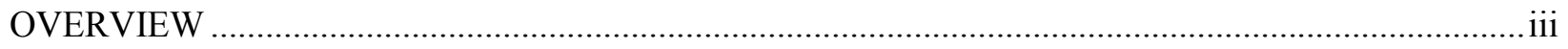

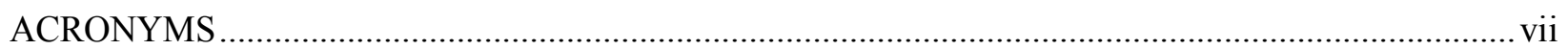

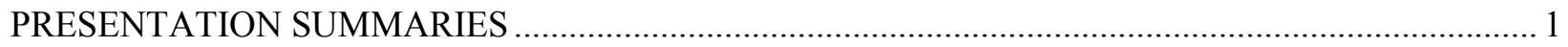

Ning Li - HLM Technology and Experimental Facility Review ................................................. 1

Jim Sienicki - Overview of the Small Secure Transportable Autonomous Reactor and Research and Development Needs .............................................................................................. 4

Mitch Farmer - Designs for HLM Test Facilities ......................................................... 6

Paul Demkowicz - Lead Coolant Test Facility Design Considerations ........................................ 7

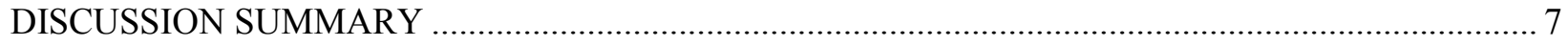

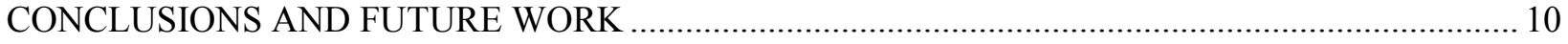

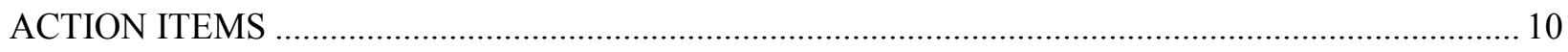

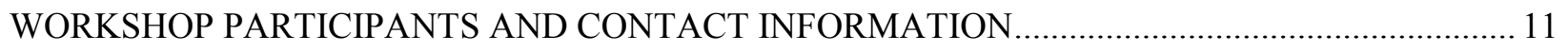

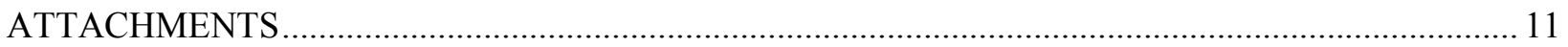

\section{TABLES}

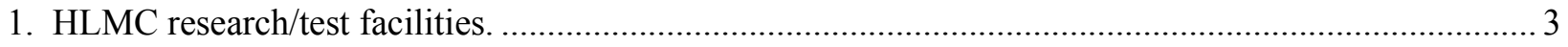

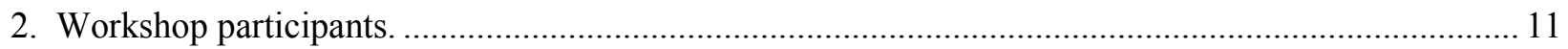





\section{ACRONYMS}

ANL Argonne National Laboratory

HLM heavy liquid metal

HLMC heavy liquid metal coolant

HX heat exchanger

LBE lead-bismuth eutectic

LFR lead-cooled fast reactor

OECD Organization for Economic Co-operation and Development

SSTAR Small Secure Transportable Autonomous Reactor 


\section{Lead Coolant Test Facility Design Workshop \\ PRESENTATION SUMMARIES}

\section{Ning Li - HLM Technology and Experimental Facility Review}

Ning Li from Los Alamos National Laboratory opened the meeting with a presentation that reviewed some salient issues in heavy liquid metal coolant (HLMC) technologies before describing some of the major HLMC test facilities around the world (Attachment 1). This includes research in Organization for Economic Co-operation and Development (OECD) countries, as well as a separate discussion of Russian work.

Some of the major research and development $(\mathrm{R} \& \mathrm{D})$ programs in lead-alloy coolant technology were reviewed, including ongoing work in the U.S., European Union, Russia, Japan, and South Korea. Research in the European Union is focused exclusively on Accelerator Driven System applications, where lead-bismuth eutectic (LBE) is studied as a spallation target. Russian work on the other hand is focused on the development of lead-cooled fast reactors. The remaining countries are interested in both types of technologies.

The discussion of technological issues included the topics of coolant oxygen control strategies, oxygen sensor development, materials corrosion issues and materials selection criteria, heavy liquid metal (HLM) thermal hydraulics, pumping and circulation methods, and instrumentation/measurement techniques.

The dominant method of controlling corrosion rates of materials in lead or LBE has been to control the oxygen levels in the coolant. The basis of this method of corrosion control is to allow a protective oxide film to form on metal surfaces, which can greatly slow the rate of further oxidation and dissolution of the metal. This is done by striking a balance between extremely low oxygen concentrations, which will result in dissolution of the metal, and excessively high oxygen concentrations, which will result in the formation of oxide slag $(\mathrm{PbO})$ in the coolant and subsequent fouling of flow channels. A number of experimental methods for oxygen control have been implemented. The most important of these are the addition of controlled $\mathrm{H}_{2} / \mathrm{H}_{2} \mathrm{O}$ gas mixtures, and the use of $\mathrm{PbO}$ as a solid mass exchanger. The former method has been extensively studied, both in Russia and in recent facilities in Europe. The latter method has not been studied to the same extent, but is considered to be a very promising method for large systems.

The materials that are suited for service in high temperature molten lead or LBE environments were classified into three basic categories. Class I materials consist of $\mathrm{Fe}-\mathrm{Cr}-\mathrm{Si}$ steels, used in conjunction with suitable oxygen control strategies. These materials are generally appropriate for use up to $550-600^{\circ} \mathrm{C}$ and are considered to be relatively mature and currently available for HLM applications.

Class II materials consist of standard steels with improved surface properties or oxygen dispersion strengthened steels. This class of materials is also intended to be used with coolant oxygen control, and can be used up to $600-700^{\circ} \mathrm{C}$. Current R\&D is focused primarily on this class of materials, and often involves tailoring the composition to enhance corrosion resistance while maintaining adequate thermomechanical properties. Adjusting the amount of $\mathrm{Cr}$ and $\mathrm{Si}$ in steels, for example, can result in superior corrosion resistance as demonstrated by the Russian-developed EP823 steel alloy. Various methods of surface treatment or alternate strategies of corrosion protection are being explored, including aluminum additions to steel surfaces (and subsequent formation in-service of a protective oxide layer), $\mathrm{Zr}$ and $\mathrm{Ti}$ added to the coolant to form carbide/nitride layers on low-alloy steels in-situ, and other surface treatment 
methods, such as shot-peening (which creates a hardened surface layer by plastically deforming the material) or the creation of a corrosion resistant amorphous surface layer.

Class III materials are suitable for use up to $700-1000^{\circ} \mathrm{C}$ and are currently not a mature technology. These consist of refractory metals ( $\mathrm{W}, \mathrm{Ta}, \mathrm{Mo}, \mathrm{Nb}$ ) and alloys, ceramics, and ceramic composites. These materials would be used in systems that are oxygen-free, as they are virtually insoluble in molten lead and do not require stable oxide layers for corrosion protection. Considerable obstacles must be overcome to realize the implementation of these materials in HLM systems, such as fabrication and joining methods for ceramics.

Ning briefly discussed a framework that is in development to model the oxidation/corrosion of steels in lead-alloys. This involves the interplay between such parameters as mass transport in the coolant, local equilibria in the boundary layer, and surface kinetics of oxide growth. A stable (surface passivating) oxide film grows by a parabolic rate law, and weight loss usually becomes linear in the steady state. It was noted that HT9 steel with a stable, protective oxide film has been shown to lose $\sim 10 \mu \mathrm{m} /$ year at $550^{\circ} \mathrm{C}$, and the implications of this number for current LFR designs were briefly discussed. In particular, such a weight loss rate would result in $\sim 0.2 \mathrm{~mm}$ loss over the 20 -year core lifetime, most likely an unacceptable amount for prototypical cladding thicknesses. Ning feels that while this rate would necessarily increase at higher temperatures, improvements can be made to the integrity and protection provide by the oxide by improving the oxygen control methods.

Thermal hydraulics considerations for $\mathrm{Pb} / \mathrm{LBE}$ were not discussed in detail. It was noted that these are low Prandl number fluids and that there appears to be a 10-20\% reduction in the Nusselt number correlation compared to experiments with $\mathrm{Na}$.

Four main types of pumping/circulation techniques for $\mathrm{Pb} / \mathrm{LBE}$ are: (1) natural circulation, (2) electromagnetic, (3) gas lift, and (4) centrifugal. Natural convection is of particular interest because it is a critical element in making the case for passive safety in a reactor, and there is a significant need for validation of thermal gradient driven flow characteristics around complex geometries. Gas lift is being considered as a viable means of augmenting flow in a natural circulation system without pumps, but considerable R\&D is needed in this area. Electromagnetic pumps are suitable for smaller experiments, but generally have a low efficiency, cause a great deal of coolant heating, and are considered impractical at this time for large systems. Centrifugal pumps have performed well in large loops and are stable and reliable, although they can be susceptible to corrosion/erosion of the impellers, a problem that is compounded with higher temperatures. Work is needed for the scale-up of these pumps for high capacity systems.

Currently deployable technologies exist for measurement of pressure, temperature, liquid metal level, and mass flow. In addition, a number of methods for coolant flow measurement are under development. An online corrosion measurement technique (e.g., electric impedance spectroscopy) is currently in the experimental stage.

There are over 30 major HLMC research/test facilities in operation or development worldwide (excluding work in Russia). These facilities are focused in a number of technical areas, including HLM technology, liquid metal chemistry, materials testing, thermal hydraulics, and irradiation tests. Fourteen specific facilities were reviewed in detail (see Table 1), including the experimental objectives and operational parameters. A majority of these facilities are focusing on LBE as coolant, but the amount of work with pure $\mathrm{Pb}$ is increasing. 
Table 1. HLMC research/test facilities.

\begin{tabular}{|l|l|l|}
\hline \multicolumn{2}{|c}{ Facility Name } & \multicolumn{2}{c|}{ Affliation } \\
\hline CIRCE & Italy & ENEA \\
\hline THESYS & Germany & FZK \\
\hline DELTA & US & LANL \\
\hline STELLA & France & CEA \\
\hline LECOR & Italy & ENEA \\
\hline CORRIDA & Germany & FZK \\
\hline LBE Loop & Japan & CRIEPI \\
\hline Lead Correlation Stand & US & LANL \\
\hline Pb/LBE Corrosion & Korea & KAERI \\
\hline THEADES & Germany & FZK \\
\hline HELIOS & Korea & KAERI \\
\hline TALL & Sweden & RIT \\
\hline Steam Lift Pump & Japan & TITech \\
\hline TC-1 & US & UNLV \\
\hline
\end{tabular}

Some of the technology gaps that still exist include:

- Integral systems with near-prototypic temperature and flow conditions

- $\quad$ Large-scale pool-type system operational experience

- Coolant chemistry control

- $\quad$ Long-term corrosion rates and irradiation effects

- Gas/steam lift pump issues

- $\quad$ Freeze/thaw concerns

- In-service inspection, maintenance and repair

- $\quad$ Coupling to secondary systems.

The majority of lead-cooled fast reactor development work has taken place in Russia. The development program there has spanned decades, beginning with nuclear powered submarines in the 1950s. Early experience on submarine power plants resulted in the fastest vessels in the fleet, but a failed reactor resulted in radiation exposure and the deaths of several crew members. The failure was found to be due to the production of oxide slag in the coolant which blocked flow channels. The result of these experiences was a better appreciation and understanding of coolant chemistry control issues. Russian reactor experience to date consists of a total of eight submarine reactors, two ground prototype reactors, many corrosion and thermal hydraulic loops and test apparatuses, and a number of institutes that support lead reactor development, including Institute of Physics and Power Engineering.

It was also pointed out that a significant amount of metal-cooled reactor experience does exist in the world (including the U.S.) in the form of sodium-cooled systems (e.g., EBR-I \& II, FFTF, JOYO, MONJU, PHENIX, SUPERPHENIX, BOR-60, BN-600, and BN-800). It is reasonable to believe that 
some of the expertise and technology in this area (thermal hydraulics, instrumentation, component development and testing) can be applied to HLMC technology development.

Ning briefly discussed the development of the OECD Heavy Liquid Metal Coolant Handbook, a cooperative effort among participating countries to develop an extensive database in coolant technology. The Handbook will include sections on $\mathrm{Pb} / \mathrm{LBE}$ properties and chemistry, materials for HLM environments, corrosion control strategies, thermal hydraulics issues, instrumentation technology, existing experimental facilities, and safety issues. The first draft of the Handbook is due to be released for review in July 2005.

The final slide from this presentation introduced some ideas for the new next generation test facility. The suggestions are that this be a pool-type, near full height scaled vessel with a drain/storage tank. The internals should be reconfigurable. A key aspect should be the ability to achieve threedimensional flows.

\title{
Jim Sienicki - Overview of the Small Secure Transportable Autonomous Reactor and Research and Development Needs
}

\begin{abstract}
Jim Sienicki of the Argonne National Laboratory (ANL) gave a presentation (see Attachment 2) that detailed the LFR design concept, the Small Secure Transportable Autonomous Reactor (SSTAR). This is a small modular fast reactor with lead as the primary coolant. The reactor features include proliferation resistance, a large increase in uranium utilization over LWRs, passive safety, and autonomous load following behavior. The proliferation resistance of this reactor is due to a sealed cartridge core with a long refueling interval (20 years). The SSTAR is a 45MWt (20MWe) reactor that is designed to meet a need for power generation in geographic regions that lack a major electrical grid. This could include developing nations and remote cities (such as in Alaska, Hawaii, or island nations), or other locations that are off-grid but require large energy supplies (such as remote mining operations). It is noted that the design is scalable to $400 \mathrm{MWt}(181 \mathrm{MWe})$.
\end{abstract}

Supercritical carbon dioxide is used in the primary heat exchangers, which utilize Brayton cycle energy conversion. This results in $44 \%$ plant efficiency at a $566^{\circ} \mathrm{C}$ core outlet temperature. The use of supercritical $\mathrm{CO}_{2}$ results in very small turbines and compressors $(\sim 0.4 \mathrm{~m}$ turbine length and diameter without casing).

The SSTAR has a compact core with a diameter of $1.0 \mathrm{~m}$ (for the $45 \mathrm{MWt}$ design) and a 0.8 active length-to-diameter ratio. This design reduces the burnup activity swing to near zero for a 20 -year lifetime core. The core uses nitride fuel with nearly $100 \%$ enrichment in ${ }^{15} \mathrm{~N}$ to avoid parasitic reactions in ${ }^{14} \mathrm{~N}$ and waste disposal problems due to the production of ${ }^{14} \mathrm{C}$. The nitride fuel will be bonded to the cladding with molten lead. The cladding will be a ferritic/martensitic stainless steel (HT9). Assuming a cladding thickness of $1.0 \mathrm{~mm}$, the optimal fuel pin diameter was determined to be $2.5 \mathrm{~cm}$. This minimizes the peak cladding temperature to $650^{\circ} \mathrm{C}$. Peak fuel temperature is expected to be $953^{\circ} \mathrm{C}$. The core features a low enrichment central region to reduce the burnup reactivity swing (the maximum reactivity swing is $\$ 0.96$ ) and enrichment zoning to reduce the peak-to-average power ratio. The average discharge burnup is 72 $\mathrm{MWD} / \mathrm{Kg}$ and the conversion ratio for the reactor is near unity.

Limitations on the size of the reactor vessel are imposed by rail transport (18.9-m length). The current vessel design height is $18.3 \mathrm{~m}$, but Jim mentioned their intention to reduce this if possible to the 12- $\mathrm{m}$ range. The reactor vessel diameter was selected at $3.23 \mathrm{~m}$ in order to fit the necessary components (cartridge core, internal heat exchangers). 
The best path toward eventual development of the SSTAR is determined to be the construction of a LFR Small Modular Reactor Demonstration Test Reactor. It is believed that the lower cost of the relatively small LFR SSTAR design makes the construction and operation of a prototype test demonstrator an affordable prospect relative to a large scale reactor, and therefore the demonstration plant can be a full-scale prototype. This would minimize the time to commercial deployment of an LFR, whereas a development program for a large scale advanced reactor would likely require a more phased approach, with a progression of scaled test reactors.

Finally, the SSTAR can be scaled down to a lower peak cladding temperature of $550^{\circ} \mathrm{C}$, where existing cladding materials can be used, without the further materials $\mathrm{R} \& \mathrm{D}$ efforts needed to produce materials capable of $650^{\circ} \mathrm{C}$ in the highly corrosive $\mathrm{Pb}$ environment under high neutron fluences. This could allow the use of HT9 cladding with existing dissolved oxygen level control techniques. The drop in peak clad temperatures by $100^{\circ} \mathrm{C}$ (and corresponding drop in outlet/inlet temperatures) would require the use of LBE as coolant instead of $\mathrm{Pb}$.

Jim Sienicki also gave a presentation that focused on the experimental needs for the LFR (see Attachment 3). This information has been documented previously (see references listed in Attachment 3). The R\&D needs are predominantly in the area of thermal hydraulics, although several other critical needs were also identified.

One of the common threads in the list of thermal hydraulic needs is multidimensional flow capability. The SSTAR core is a single cartridge without individual removable fuel assemblies. The open lattice design allows for significant crossflows between channels. There is therefore a need to study: (1) HLMC coolant flow in pin arrays with prototypic diameter, spacing, and height; (2) the effect of power distributions across fuel pin arrays; (3) the effects of grid spacers on coolant intermixing, frictional pressure drops, and heat transfer; and (4) diagnostic capabilities and instrumentation to measure local coolant velocities and temperatures. The data collected should also meet the requirements for validation of multidimensional computer codes.

With regard to experimental studies of the open-lattice core, there is also an interest in studying the fretting effects on tube support structures and the effect this may have on the protective oxide coatings of core materials. The effects of the surface oxide layers on frictional flow and heat transfer should also be studied.

The LFR core has strong reactivity feedbacks to changes in coolant and fuel temperatures, which enables autonomous changes in reactor power to match changes in heat removal from the primary coolant system. Thus a perturbation in coolant flow or temperature can cause a perturbation in core power that affects fuel temperatures, coolant temperatures, and flow rate. Studies of the SSTAR using onedimensional single-phase natural circulation have predicted stable behavior, but the concern is that multidimensional power, temperature, and velocity profiles might reduce this stability, possibly inducing reverse flow. Thus there is a need for experimental data that establishes ranges of stability and the conditions under which reverse flow might occur.

The startup phase for the LFR involves input of a large amount of heat to exceed the melting temperature of the coolant. Experimental needs in this area include investigation of startup transients to determine regimes in which undesirable flow patterns develop and investigation of flow-assist strategies to achieve the desired flow pattern during startup (e.g., gas lift, jet pumps). Since normal LFR operations (i.e., startup/shutdown) would involve freezing and melting of the coolant in the reactor, experimental data are needed regarding the "freeze/thaw" cycles of $\mathrm{Pb}$ and $\mathrm{LBE}$, and the extent of any associated stresses that might occur in the reactor components. 
Carbon dioxide (secondary coolant) blowdown into the HLMC (following a heat exchanger rupture) and subsequent void formation in the coolant and transport to the core region are concerns, and experiments should be conducted in this area. This should include a determination of the chemical reaction products of $\mathrm{CO}_{2}$ with $\mathrm{Pb}$ or $\mathrm{LBE}$.

The long-life core design of the SSTAR results in the possibility of operating the reactor with some failed fuel rods. Thus information should also be obtained regarding the chemical behavior of fission products in $\mathrm{Pb}$ or LBE.

Finally, gas lift pumping is seen as a viable means of augmenting the coolant flow in a natural circulation reactor. Experimental information is therefore needed regarding lift pump thermal hydraulics. This includes the flow rates of HLMCs using a lift pump, optimal lift pump designs, the extent of bubble entrainment in the coolant and introduction to the core, and diagnostics to determine void distributions.

\section{Mitch Farmer - Designs for HLM Test Facilities}

Work has been performed at ANL over the last $\sim$ four years to develop test facilities to address some of the LFR experimental needs described above. Mitch Farmer from ANL summarized this work and presented a design for an integrated HLM test facility (see Attachment 4).

It was noted that separate facilities are need to address thermal hydraulic and corrosion R\&D needs. Corrosion is currently being studied effectively in various facilities (e.g., DELTA, HARP), therefore the proposed facilities need to focus on thermal hydraulics issues. The current ANL approach is to construct two separate thermal hydraulic research facilities: (1) a large scale integral facility to create prototypic natural circulation conditions that are expected in the LFR, and (2) a reduced scale facility that can be used to develop instrumentation and hardware to support the large scale facility and address issues that would be impractical to investigate at the larger scale.

ANL believes that the large scale facility requires a full-height apparatus $(12-15 \mathrm{~m})$ to meet the identified thermal hydraulic experimental needs, and the design reflects this requirement. A scaling study has been presented (see references in Attachment 4) justifying this approach. The design consists of concentric cylinders, with the inner cylinder (6-inch ID) containing a mock-up of a fuel pin array using electrically heated rods. The outer cylinder (16 inches) is the downcomer, with a heat exchanger placed in this outer annular region at the top of the vessel. The 19 heated pins of the simulated core are $2 \mathrm{~m}$ in length and are placed in a triangular array, which is deemed to be of sufficient size to simulate important power profile effects. They would have a linear power density of $300 \mathrm{~W} / \mathrm{cm}$. The power would be independently controlled for each rod, in order to simulate radial core power distribution and transients. The use of multiple heated zones on each rod could also be used to allow for axial power distribution simulations.

The outer pipe will be made of $316 \mathrm{~L}$ stainless steel, which is suitable for the $540^{\circ} \mathrm{C}$ maximum operating temperature of the facility, and is designed to withstand the loads generated from a $\sim 15 \mathrm{~m}$ column of lead. The overall electrical power requirement for the facility would be $1.5 \mathrm{MW}$. The coolant is LBE.

The heat exchanger (HX) will be designed with the objectives of providing a mock-up of the prototype U-tube HX currently envisioned for the LFR and engineering the system so that coolant temperature can be varied in the range of interest. Verification of various HX concepts is expected to be one of the main experimental activities for this facility. 
The overall design approach is to build the facility in a modular fashion. In this way the cost of achieving a full $12-15 \mathrm{~m}$ height vessel is realized incrementally. The weight of a $\sim 12-\mathrm{m}$ facility of this design is about 19 tons. Based on this preliminary design work, the estimate is that it would take $\sim$ three years and \$3-4M to deploy and do shake-down testing of this facility. It should be noted that this estimate assumes that some existing infrastructure (including a heavy duty steel frame and a sufficient electrical power supply) is already in place.

The second, reduced scale test facility mentioned above is currently in development at ANL and dubbed HELMET (Heavy Liquid Metal Test facility). This project is seen as a demonstration bed for the technology that will be implemented in the larger test facility. The design is similar, although the cylinder diameters are decreased (20.2-cm outer annulus diameter) and the number of simulated fuel rods is decreased to seven. The approach is the same as the large scale design, with electrically heated simulate fuel rods to represent a core. The fuel rod simulators are $18 \mathrm{~mm}$ in diameter, have a $1 \mathrm{~m}$ heated length, and a power density of $170 \mathrm{~W} / \mathrm{cm}$.

Based on consideration of ASME codes for the materials of construction (316 stainless steel), the maximum operating temperature for this facility is listed as $815^{\circ} \mathrm{C}$ (this figure does not take into account the issue of lead corrosion at elevated temperatures, and triggered the comment that this temperature could never be realistically reached in a stainless steel vessel containing lead or lead-alloy). The overall height of the first module (keeping with the modular approach) is $2.5 \mathrm{~m}$.

The HELMET facility is being designed and constructed at ANL with LDRD funding. Design and construction activities are continuing in FY 2005. FY 2006 should see the completion of construction and initiation of demonstration tests.

\section{Paul Demkowicz - Lead Coolant Test Facility Design Considerations}

Paul Demkowicz of the Idaho National Laboratory gave a brief presentation outlining some important design considerations of the proposed test facility (see Attachment 5). A report has been prepared at the INL (see Attachment 6) that discusses many of the important design consideration, R\&D needs, facility requirements, and safety considerations. This is intended to present a starting point for design discussions for the test facility. Some of the important design criteria that are outlined in this report include an emphasis on experimental flexibility, interchangeable components and the ability to support a variety of experiment configurations, a large pool vessel to contain large assemblies, the ability to explore pumping options, and coolant clean-up capability.

Some of the experimental needs were discussed and the related facility design parameters that must be addressed. These include the use of $\mathrm{Pb}$ vs. $\mathrm{LBE}$, the temperature range for the apparatus, facility dimensions (including volume of HLMC), power requirements, pumping options, coolant chemistry control methods, oxygen sensor technologies, coolant flow measurement techniques, and instrumentation.

\section{DISCUSSION SUMMARY}

Following the presentations summarized above, discussions were held to determine the experimental scope of the proposed test facility at INL, the functional requirements of this facility, possible costs and schedules associated with this development effort, and the next steps that should be taken. A summary of these discussions is presented here.

A key element of the proposed facility is whether or not this should use $\mathrm{Pb}$ or LBE as the working fluid. LBE has often been used in reactors (Russian experience), in Accelerator Driven System facilities, and in experimental systems because of the significantly lower melting point of $\operatorname{LBE}\left(125^{\circ} \mathrm{C}\right) \mathrm{vs} . \mathrm{Pb}$ 
$\left(327^{\circ} \mathrm{C}\right)$. This difference means that heating requirements are greatly reduced and overall operating temperatures - particularly of reactors - can be lower without the potential danger of inadvertent freezing of the coolant. Lower temperatures in turn significantly reduce material corrosion rates and allow for the use of conventional, code-qualified materials (e.g., austenitic 316 stainless steel) for very long test durations. However, in the current case there is a significant incentive to use $\mathrm{Pb}$ as the working fluid, since this facility is intended to provide a demonstration of technologies that will be used in a $\mathrm{Pb}$-cooled demonstration reactor. There was no definite consensus during the discussions on this issue. It was suggested by several participants that proper design of the facility with multiple transfer and storage tanks could allow the use of both coolant compositions without excessive costs incurred. The small amount of bismuth contamination that would result in the pure $\mathrm{Pb}$ by sharing the same apparatus with LBE is not deemed to be a significant issue, since (1) this would most likely have a very minor effect, if any, on coolant physical properties, and (2) this is not an irradiation facility, where activation of Bi to ${ }^{210} \mathrm{Po}$ would result in a major radiological hazard. While the $\mathrm{Pb}$ vs. LBE issue might be resolved during a preconceptual design and cost estimate phase, this solution (dual coolant compositions) could obviate the need for a selection, as well as add a unique capability to the facility.

It was noted that there is a potential time constraint placed on this development effort due to the development schedule of the Generation IV program (as outlined, for example, in the Generation IV Ten-Year Plan 2005). This schedule suggests a fast reactor down select in the vicinity of 2010-2012. Assuming that roughly three to four years of data collection from an engineering test facility would be needed as input for these programmatic decisions, this suggests that the test facility should be operational in FY 2008 or FY 2009. This in turn requires that a major design/construction effort commence immediately (FY 2006) in order to meet this schedule. This imposes an implied fiscal constraint on the project; i.e., a total project cost in excess of $\$ 5 \mathrm{M}$ will require inclusion in the DOE budget as a line item. Since FY 2007 budgets are currently being set, the earliest this could be included would be FY 2008, if a Critical Decision (CD)-0 is prepared by June 2006. Hence there is a motivation to keep the project cost within this prescribed limitation if a near-term deployment is to be achieved.

However, the opinion was expressed by several participants that this monetary limit would be detrimental to achieving the desired scope for this facility, since it is intended to be a test bed for a variety of technologies in addition to providing thermal hydraulics data to verify computational fluid dynamics codes. It is believed (based on current experience, but conceding that detailed cost estimates have not been prepared) that achieving the necessary goals could require a budget in the $\$ 10-20 \mathrm{M}$ range, and possibly higher. This is particularly pertinent in light of the fact that this test facility will be considered a direct precursor to deploying a demonstration test reactor. Thus the introduction of the concept of "steps," or a phased approach to development, suggesting that moving from the existing facilities in the U.S. (e.g., DELTA loop) with development costs (and corresponding experimental scope) in the range of several million dollars, to a $\$ 500 \mathrm{M}+$ advanced demonstration reactor would be an unacceptably large step from an engineering point of view.

So there is somewhat of a dilemma between pushing for a more rapid development schedule for the test facility (and by necessity a relatively low cap on the total project cost) to meet the Generation IV LFR timeline, versus proceeding with a more comprehensive (and expensive) test facility and accepting the inescapable consequence of a longer development timeline. Ultimately this issue should be resolved by a critical assessment of the LFR R\&D needs, the necessary facility requirements to meet these needs, and the corresponding cost of the envisioned facility. At this stage of development and planning, this is seen as the key issue, and it is proposed that this be addressed this year (provided funding is available) or early in FY 2006. The ANL facility design (presented by Mitch Farmer, see Attachment 4) gives an excellent example of something that can be achieved for $\angle \$ 5 \mathrm{M}$ (the ANL rough estimate is $\$ 3-4 \mathrm{M}$ ). This debate therefore centers on whether the proposed ANL design is adequate to meet the critical R\&D needs and 
provide the necessary technology step to proceed with a demonstration reactor. We will need to decide if there is a sufficient justification for a larger facility.

The ANL test facility design was discussed briefly. The general consensus seemed to be that this was a very good facility design. The issue of facility dimensions is relevant here, however, and there was some question as to whether some of the desired experiments (core diagnostics, in-service inspections, swapping of internal structures, etc.) could be adequately performed with a "core" region of the size envisioned. By means of comparison, the CIRCE pool-type facility in Brasimone, Italy, utilizes fullheight $(8.5 \mathrm{~m})$, reduced diameter (1.2-m OD) vessel that contains 90 metric tons of LBE. The full-height design by ANL has a diameter of $0.4 \mathrm{~m}$ and a total mass (for a 12-m vessel height) of $\sim 19$ tons. Mitch Farmer commented that while the ANL design in general achieves many of the LFR R\&D objectives, it does not adequately represent a realistic input plenum geometry or address core fretting concerns.

Questions about in-service inspection technology development were raised. In particular, it has been noted that the Russian BREST reactor may present significant inspection difficulties. These are related in part to the high coolant temperature (by necessity significantly above the $327^{\circ} \mathrm{C}$ melting point of $\mathrm{Pb}$ ). This causes difficulties in worker access to coolant-related sectors of the plant, as the radiant heat from the cold-side of coolant tanks and conduit is significant.

Bill Halsey noted that the LFR SSTAR concept is intended by design to require little or no inservice inspection, since this is a sealed, long-lifetime core reactor. However, any coolant technology test facility (and subsequent demonstration reactor) would need to be designed to allow inspections to verify the performance of materials and structures. It is not clear at this stage of development how in-service inspection will be accomplished in a test facility.

Some additional comments and discussion synopses are summarized below:

- The opinion was expressed that "coatings", in the traditional sense, are not the optimal avenue for materials protection. Rather, the methodologies under serious consideration are surface treatments or gradient materials. The distinction being made here is between applied layers that are distinct from the substrate (and subject to adhesion problems) versus surface layers that are microstructurally somewhat continuous with the underlying substrate. The latter tend to exhibit superior performance, particularly with regard to spallation resistance.

- $\quad$ The question was asked: "What materials would be used for an LFR if one was to be built tomorrow." The quick answer is austenitic steel (316 SS) for the reactor vessel and ferritic/martensitic steel (HT9 or T91) for the clad, with nitride fuel pellets. The use of these materials assumes relatively low peak cladding temperatures (perhaps below $550^{\circ} \mathrm{C}$ ) and the use of coolant oxygen control techniques to stabilize the protective oxide on these materials. The lower operating temperatures would most likely necessitate the use of LBE instead of $\mathrm{Pb}$.

- $\quad$ Regarding materials of construction for the test facility, the observation was made that different regions of the experimental apparatus will be at different temperatures. This means that some of the sections can be built out of more conventional materials (e.g. 316 stainless steel), as they will not need to resist very high temperature corrosion. The approach could be to design hightemperature sections to be relatively easily replaced, so that the facility life is not limited by materials corrosion in these critical sections.

- It was noted during discussions that diagnostics for coolant flow velocities in a complex geometry like a simulated core are extremely difficult. Currently no such techniques are available, and this may hinder the usefulness of these experiments (e.g., determining flow fields in coolant channels 
within a simulated fuel rod array). It was pointed out, however, that it is often possible to derive flow profiles by measuring the temperature distribution, and this may be an approach to be applied in this case.

- It was noted that the process to complete ASME code qualification for a new material requires $\sim$ seven years to complete. This has obvious implications for the "near-term" deployment of a reactor using currently non-qualified materials.

- Jim Sienicki noted that this test facility is specifically intended to support an LFR test demonstration reactor, as opposed to the final LFR design. The real issue is acquiring the necessary data to be able to make a case for developing an LFR demonstration test reactor, and this needs to be accomplished by the proposed test facility.

- At several points during the discussion it seemed clear that the LFR program and HLM technology development in the US in general could benefit from better collaboration among investigators, in order to make better use of limited funding and resources and avoid needless duplication of experimental work. This should be a goal of the working group(s) that are established in this area.

- $\quad$ ANL has previously prepared a prioritized list of LFR R\&D needs, and can make this available. The workshop chair will contact Mitch Farmer to obtain a copy of the prioritized list.

\section{CONCLUSIONS AND FUTURE WORK}

The workshop highlighted the important issues that need to be addressed in developing a next generation test facility and encouraged some fruitful discussions on the R\&D needs and experimental scope of the proposed facility.

Further work is needed to reach a decision on the design specifics of this facility. It was decided that a working group should be established to address these issues and come to a consensus on the minimum magnitude of the facility that is needed to meet the necessary R\&D needs. If a larger facility is justified, the path forward will be to prepare a conceptual design, requirements, need justification, safety considerations, and a schedule by May of 2006 in ordered to submit a CD-0 in time for placement in the FY 2008 budget. It is expected that this proposed work in FY 2006 will also resolve some of the specific facility issues that were discussed at this meeting by working through a preliminary design and cost estimate process.

The most immediate need is to charter the working group and decide on a prioritized list of LFR R\&D needs, which will then lead to a list of correlated facility requirements or capabilities. This "Needs and Requirements" matrix will be the basic tool used to determine the necessary scope of the proposed test facility. Specifically, this will allow the identification of the critical capabilities that might be sacrificed in developing a reduced-scope facility.

\section{ACTION ITEMS}

1. Prepare a summary of the meeting and distribute to participants for comments/edits (P. Demkowicz).

2. Disseminate presentation slides to participants (P. Demkowicz).

3. Establish a working group on LCTF development (P. Demkowicz to organize). 
4. Ning Li will send Paul Demkowicz an LBE technology R\&D matrix that was previously developed at LANL.

5. Workshop chair will contact ANL to discuss the LFR R\&D needs matrix and prioritization list (P. Demkowicz, M. Farmer).

\section{WORKSHOP PARTICIPANTS AND CONTACT INFORMATION}

Table 2. Workshop participants.

\begin{tabular}{|llll|}
\hline Name & Affliation & Email & Phone \\
\hline Ron Ballinger & MIT & $\underline{\text { hvymet@mit.edu }}$ & $617-253-5118$ \\
Mike Capiello & LANL & $\underline{\text { mcappiello@lanl.gov }}$ & $505-665-6408$ \\
Paul Demkowicz & INL & $\underline{\text { Paul.Demkowicz@inl.gov }}$ & $208-526-3846$ \\
Mitch Farmer & ANL & $\underline{\text { farmer@anl.gov }}$ & $630-262-8218$ \\
Irina Glagolenko & INL & $\underline{\text { glagiy@inel.gov }}$ & $208-533-7381$ \\
Bill Halsey & LLNL & $\underline{\text { halsey1@|lnl.gov }}$ & $925-423-1133$ \\
Steve Herrmann & INL & $\underline{\text { steve.herrmann@anlw.anl.gov }}$ & $208-533-7859$ \\
Pat Kern & INL & $\underline{\text { Patrick.Kern@inl.gov }}$ & $208-533-7333$ \\
Ron King & INL & $\underline{\text { Ronald.King@inl.gov }}$ & $208-526-3660$ \\
Sue Lesica & GenIV/AFCI & $\underline{\text { Sue.Lesica@nuclear.energy.gov }}$ & $301-903-8755$ \\
Ning Li & LANL & $\underline{\text { ningli@lanl.gov }}$ & $505-665-6677$ \\
Steve Lomperski & ANL & $\underline{\text { lomperski@anl.gov }}$ & $630-262-1144$ \\
Jian Ma & UNLV & $\underline{\text { ianma@egr.unlv.edu }}$ & $702-895-5055$ \\
Theron Marshall & INL & $\underline{\text { Theron.Marshall@inl.gov }}$ & $208-526-4760$ \\
Kemal Pasamehmetoglu & INL & $\underline{\text { Kemal.Pasamehmetoglu@inl.gov }}$ & $208-526-5305$ \\
Jim Sienicki & ANL & $\underline{\text { sienicki@anl.gov }}$ & $630-252-4848$ \\
Manohar Sohal & INL & $\underline{\text { Manohar.Sohal@inl.gov }}$ & $208-526-9412$ \\
Dan Wachs & INL & $\underline{\text { Daniel.Wachs@inl.gov }}$ & $208-533-7604$ \\
John Yankeelov & DOE-ID & yankeeja@id.doe.gov & $208-526-7049$ \\
\hline
\end{tabular}

\section{ATTACHMENTS}

1. Ning Li, "Heavy Liquid Metal (LBE, Pb) Test Facilities: Overview of Existing Facilities in OECD Countries," Presentation at the Lead Coolant Test Facility Design Workshop, Idaho National Laboratory, Idaho Falls, Idaho, May 25, 2005.

2. Jim Sienicki, "Small Secure Transportable Autonomous Reactor (SSTAR)," Presentation at the Lead Coolant Test Facility Design Workshop, Idaho National Laboratory, Idaho Falls, Idaho, May 25, 2005.

3. Jim Sienicki, "LFR Thermal Hydraulic Experiment Data Needs," Presentation at the Lead Coolant Test Facility Design Workshop, Idaho National Laboratory, Idaho Falls, Idaho, May 25, 2005.

4. Mitch Farmer, "Thermal Hydraulics Test Facility Design for Addressing Key LFR Data Needs," Presentation at the Lead Coolant Test Facility Design Workshop, Idaho National Laboratory, Idaho Falls, Idaho, May 25, 2005.

5. Paul Demkowicz, "INL Lead Coolant Test Facility (LCTF): Design Criteria and Considerations," Presentation at the Lead Coolant Test Facility Design Workshop, Idaho National Laboratory, Idaho Falls, Idaho, May 25, 2005. 
6. Eric Loewen, "Idaho National Laboratory Lead or Lead-Bismuth Eutectic (LBE) Test Facility," Idaho National Laboratory Report INL/EXT-05-00267, 2005. 